\title{
Implementasi Aplikasi SIKS sebagai Electronic Records Management System (ERMS) di Arsip UGM
}

\section{$\begin{array}{llllllll}\text { I } & \mathbf{N} & \mathbf{T} & \mathbf{I} & \mathbf{S} & \mathbf{A} & \mathbf{R} & \mathbf{I}\end{array}$}

Pengelolaan arsip sangat penting untuk diperhatikan sebab dengan adanya arsip tersebut institusi dapat mengevaluasi kinerja dan memprediksi kemungkinan-kemungkinan yang akan terjadi di masa mendatang untuk melakukan perubahan. Arsip tidak hanya berupa kertas pada era digital sekarang ini, tetapi juga dalam format digital dan elektronik. Penanganan arsip dalam bentuk kertas dan elektronik berbeda. Arsip UGM memiliki ERMS (Electronic Records and Management System) yaitu sistem yang digunakan untuk mengelola arsip elektronik. Sistem tersebut diberi nama SIKS (Sistem Informasi Kearsipan Statis). Tulisan ini bertujuan untuk mengetahui penerapan SIKS sebagai ERMS, serta menguraikan kelebihan dan kekurangan SIKS sebagai ERMS dengan harapan dapat dijadikan bahan evaluasi di Arsip UGM untuk meningkatkan pelayanan kearsipan. Hasil analisis yang dilakukan oleh penulis menunjukkan beberapa hal yang perlu dikembangkan dalam optimalisasi SIKS yaitu perlu dikembangkanya model pencarian tingkat lanjut misalnya pencarian dengan boolean operator. Selain itu, perlunya sinkronisasi data terutama setelah migrasi server, dan perlu ditambah sumber daya manusia khususnya SDM bidang IT.

\section{$\begin{array}{llllllll}A & B & S & T & R & A & C & T\end{array}$}

Records management is the very important thing to note in an institution, because of the presence of the archive, the institution can evaluate the performance and predict possibilities happen forward to make changes. In this digital era, the archive is not just a piece of paper but also available in digital or electronic format. Handling of records in paper and electronic form is different. Arsip UGM has an ERMS (Electronic Records and Document Management System) which is a system used to manage electronic records, then the system was named SIKS (Sistem Informasi Kearsipan Statis). This paper aims to determine the extent of implementation SIKS as ERMS,
PENULIS

Budhi Santoso, Thoriq Tri Prabowo

UIN Raden Fatah Palembang, UIN Sunan Kalijaga Yogyakarta

kangbudhi uin@,radenfatah.ac.id, toriq.prabowo@uin-suka.ac.id

KATA KUNCI

Arsip Elektronik, Arsip Statis, ERMS, SIKS.

KEY WORDS

electronic archives, ERDMS, SIKS, static archives.

Submitted: 05/09/2020

Reviewed: 07/10/2020

Accepted: 14/10/2020 
and outlines the advantages and disadvantages SIKS as ERMS with expectation that can be used as an evaluation at the Arsip UGM to improve service archives. From the results of the analysis done by the author of several findings that need to be developed in the optimization SIKS that need to develop an search models eg advanced searches with Boolean search operators, data synchronization importance especially after a server migration, and should be coupled human resources, especially human resources ITfield.

\section{PENGANTAR}

\section{Latar Belakang Masalah}

Kesadaran tentang pentingnya pengelolaan arsip dan kearsipan telah meningkat saat ini (Mahmudah \& Rahmi, 2016:7). Pengelolaan Arsip Indonesia masih jauh ketinggalan dibandingkan dengan negara yang telah maju pengelolaan arsipnya seperti Negara Belanda, bahkan Indonesia masih ketinggalan dalam pengelolaan arsip dibandingan negara tetangga yaitu Malaysia. Hal ini diperkuat dengan kekalahan Indonesia diplomasi dalam mempertahankan pulau Sipadan dan Ligitan di pengadilan international karena Indonesia tidak dapat menunjukkan bukti arsip yang lebih kuat dari Malaysia atas Pulau Sipadan dan Ligitan (Tempo.co, 2003).

Kesadaran arsip di tingkat institusi juga perlu ditingkatkan khususnya pengelolaan arsip di universitas (Setiawan \& Hakim, 2018: 881). Pengelolaan arsip di tingkat universitas seharusnya ditangani secara khusus oleh sebuah departemen khusus yang mengelola arsip untuk mengantisipasi kerancuan koleksi arsip dengan koleksi perpustakaan (Mutmainnah et al., 2020: 6). Pengelolaan arsip yang tidak dipisahkan antara perpustakaan dan kearsipan akan memberikan dampak pada sistem pengelolaan yang campur aduk antara arsip dan koleksi perpustakaan (Fathurrahman, 2018: 215). Kondisi tersebut kemudian mengurangi kondisi fisiknya yaitu ternilai politis dan yuridisnya tereduksi, karena dianggap telah kehabisan nilai guna. Pengelolaan seperti ini juga memiliki risiko rusak dan hilang.

Arsip diproduksi hampir setiap saat. Penggunaannya juga relatif beragam, ada yang digunakan setiap saat, ada yang digunakan sesekali saja. Arsip dinamis adalah arsip yang digunakan secara langsung dalam kegiatan pencipta arsip dan disimpan dalam jangka waktu tertentu (Rosalin, 2017:10). Istilah arsip dinamis di indonesia juga dikenal dengan istilah rekod/ rekaman. Menurut Undang- 
Undang Republik Indonesia Nomor 43 Tahun 2009 tentang Kearsipan, arsip dinamis dipergunakan secara langsung dalam perencanaan pelaksanaan, penyelenggaraan kehidupan kebangsaan pada umumnya atau dipergunakan secara langsung dalam penyelenggaraan administrasi negara (Wardah, 2017: 55). Rekaman/ rekod dalam berbagai bentuk fisik yang dihasilkan oleh organisasi atau individu dalam aktifitasnya setiap waktu, disimpan permanen untuk penggunaan di masa mendatang.

Kemajuan teknologi informasi dan komunikasi membuat perubahan besar pada seluruh aspek kehidupan manusia. Termasuk dalam hal tata kelola arsip "(Putranto, 2018: 1). Kini arsip banyak juga berwujud digital/ elektronik. Terdapat perbedaan yang sangat mendasar dalam pengelolaan arsip dinamis bentuk kertas/ tercetak dengan arsip dinamis bentuk elektronik/ digital. Electronic Records and Document Management System (ERMS) adalah sebuah sistem yang dirancang untuk mengelola arsip elektronik (Rustam, 2019: 1.13). Kajian terhadap ERMS sangatlah penting dilakukan untuk meningkatkan kualitas pengelolaan arsip elektronik.

Arsip UGM merupakan salah satu pusat pengembangan dan layanan informasi kearsipan perguruan tinggi. Arsip perguruan tinggi adalah lembaga kearsipan berbentuk satuan organisasi perguruan tinggi, baik negeri maupun swasta yang melaksanakan fungsi dan tugas penyelenggaraan kearsipan di lingkungan perguruan tinggi. Kegiatan utama yang dilakukan Arsip UGM adalah menyelamatkan arsip universitas sebagai sumber informasi dan memori kolektif UGM. Arsip UGM memiliki ERMS yang dikenal dengan SIKS (Sistem Informasi Kearsipan Statis). Tujuan SIKS adalah meningkatkan efektivitas dan efisiensi pengelolaan arsip elektronik di UGM. Pengelolaan arsip dinamis elektronik seharusnya dilakukan secara khusus tidak hanya dilakukan dari sisi administratif tetapi juga dari sisi ruang dan teknis atau perlakukan terhadap arsip itu sendiri. Artikel berikut akan menguraikan perihal implementasi SIKS sebagai ERMS di Arsip UGM dengan tujuan sebagai bahan evaluasi, agar SIKS menjadi ERMS yang ideal.

\section{Rumusan Masalah}

Berdasarkan uraian tersebut, masalah penelitian dapat ditentukan sebagai berikut: Bagaimana implementasi aplikasi SIKS sebagai ERMS di Arsip UGM?

\section{Tujuan Penelitian}

Penelitian ini bertujuan untuk mengetahui implementasi aplikasi SIKS sebagai ERMS di Arsip UGM. 


\section{Metode Penelitian}

Penelitian ini menggunakan pendekatan kualitatif, dengan fokus penelitian adalah implementasi aplikasi SIKS sebagai ERMS di Arsip UGM. Sumber data yang digunakan dalam penelitian ini adalah sumber data primer dan sekunder. Sumber data primer dilakukan melalui penggunaan SIKS secara langsung dan wawancara dengan arsiparis. Adapun sumber data sekundernya adalah berbagai literatur yang mengkaji ERMS. Teori-teori dari literatur tersebut kemudian digunakan sebagai landasan untuk melihat ERMS yang ada di Arsip UGM. Analisis data dilakukan dengan cara membuat sintesis dari pengamatan, hasil wawancara, dan analisis komprasi antara teori dan kondisi di lapangan. Langkah selanjutnya, untuk memperkuat analisis tersebut peneliti melakukan penjabaran hasil penelitian yang dilakukan secara deskriprif dan didukung dengan gambar-gambar untuk memperjelas hasil analisis.

\section{Landasan Teori}

\section{Lembaga Arsip Universitas}

Arsip Universitas adalah sebuah program yang terkait dengan kebijakan, sumber daya manusia, koleksi arsip yang dimiliki, dan fasilitas gedung untuk melestarikan dan membuat agar warisan dokumenter dari suatu lembaga pendidikan tinggi dapat diakses
(Setiawan \& Hakim, 2018: 47). Dokumendokumen tersebut semakin bertambah sebagai konsekuensi logis dari bertambahnya kegiatan dan aktivitas baik yang bersifat akademik, maupun nonakademik (Prabowo, 2020: 17). Dokumen-dokumen tersebut adalah dokumen terpilih dan dikelola secara sistematis berdasarkan teori kearsipan dan teknis pengelolaan arsip (Maher, 1992: 16).

Keberadaan Arsip Universitas membuat adanya unit kerja yang khusus menangani tugas-tugas kearsipan akan membantu menyelamatkan hilangnya memori kolektif lembaga universitas. Selain itu, arsip universitas dapat mendukung visi dan misi organisasi dalam mendukung research university sehingga hasil penelitian yang dilakukan akan menjadi acuan, arsip yang terkelola dengan baik(Mutmainnah et al., 2020: 5).

\section{Manajemen Arsip Elektronik}

Istilah manajemen arsip dinamis (records management) merupakan istilah kompleks yang membutuhkan batasan dan pengertian yang hati-hati. Satu alasannya adalah tidak adanya batasan universal mengenai arsip (record). Pada kenyataannya, informasi yang direkam dalam berbagai macam cara dapat menjadi arsip, bergantung pada siapa yang memberikan batasan atau pengertian (Irawan, 2001: 10). 
Rekaman/ rekod dalam konteks ini adalah arsip dinamis. Arsip dinamis adalah arsip yang digunakan secara langsung dalam kegiatan pencipta arsip dan disimpan selama jangka waktu tertentu (Undang-Undang Republik Indonesia Nomor 43 Tahun 2009 tentang Kearsipan, pasal 1 ayat 3). Arsip dinamis elektronik adalah arsip dinamis yang memiliki format elektronik atau digital dan memerlukan media tertentu sesuai dengan bentuk arsipnya untuk membacanya.

Manajemen arsip merupakan kegiatan yang bertanggung jawab untuk mengontrol penciptaan, penerimaan, pemeliharaan, penggunaan, dan disposisi rekaman/ rekod, termasuk proses untuk memperoleh dan mempertahankan bukti dan informasi tentang kegiatan bisnis dan transaksi dalam bentuk rekaman/ rekod secara sistematis dan efisien --(International Standardization Organization, 2001: 3). Siklus Arsip elektronik memiliki perbedaan dengan arsip manual, proses penciptaan dan penyimpanan pada arsip elektronik dilangsungkan dalam satu tahap, distribusi dan penggunaan dilakukan dalam satu tahap. Oleh karena itu, siklus hidup dan pengelolaan arsip elektronik lebih efisien (Hendrawan \& Ulum, 2017: 84).

Adapun pengelolaan arsip dinamis meliputi: kaptur, registrasi, klasifikasi, klasifikasi akses dan keamanan, identifikasi status keamanan, identifikasi status penyusutan, penyimpanan, penggunaan dan pelacakan, serta pelaksanaan penyusutan - (International Standardization Organization, 2001). Meskipun proses yang dikemukakan seakan berurutan, namun pada arsip elektronik proses tersebut dapat berlangsung secara simultan atau urutannya berbeda dari yang dikemukakan. Setiap proses menghasilkan metadata (deskripsi atau profil sebuah dokumen atau objek informasi lainnya) sebuah dokumen yang dihubungkan ke arsip yang bersangkutan (Azmi, 2008: 116).

Sama seperti pekerjaan pada bidang yang lain, pengelolaan arsip juga harus dilakukan oleh profesional. Undang-Undang Republik No. 43 Tahun 2009 menyebutkan bahwa lembaga arsip harus ditangani profesional yang disebut dengan arsiparis. Arsiparis adalah seseorang yang memiliki kompetensi di bidang kearsipan yang diperoleh melalui pendidikan formal dan/ atau pendidikan dan pelatihan kearsipan serta mempunyai fungsi, tugas, dan tanggung jawab melaksanakan kegiatan kearsipan (Undang-Undang Republik Indonesia Nomor 43 Tahun 2009 tentang Kearsipan, 2009, pasal 1 ayat 10). Arsiparis bisa dibantu oleh SDM lain yang memiliki kompetensi dan profesionalitas bidang 
kearsipan (Undang-Undang Republik Indonesia Nomor 43 Tahun 2009 tentang Kearsipan, 2009, pasal 30 ayat 1).

ERMS adalah satu bagian dari Business Information Systems (BIS) yang tujuan utamanya adalah untuk mengkaptur dan mengatur arsip digital. ERMS adalah sistem yang dirancang secara khusus untuk mengatur penciptaan, penggunaan, perawatan, dan pembuangan arsip digital untuk tujuan menyediakan bukti aktiviatas bisnis (Hendrawan \& Ulum, 2017: 73).

Impementasi arsip dengan ERMS memiliki kelebihan yaitu sebagai metode untuk memelihara arsip-arsip elektronik sepanjang waktu dengan perlindungan yang diperlukan dalam rangka preservasi arsip jangka panjang (Rustam, 2019: 1.13).

Adapun keuntungan lain dari implementasi ERMS adalah sebagai berikut:

a. Informasi kontekstual dan metadata d a pat terpelihara, serta memungkinkan identifikasi disetiap link, mendukung nilai kebuktian dan akses dapat dilakukan sepanjang waktu;

b. Melakukan proses-proses pengelolaan arsip, yaitu klasifikasi, registrasi, pencarian dan temu balik, preservasi dan penyusutan; dan

c. Kontrol terhadap arsip dapat dilakukan dengan mudah seperti kontrol akses dan keamanan arsip.

\section{PEMBAHASAN}

\section{Implementasi Aplikasi SIKS sebagai ERMS di Arsip UGM}

Tahun 2011 Arsip UGM membuat SIKS (Sistem Informasi Kearsipan Statis) yang memiliki tujuan utama sebagai alternatif alat bantu pencarian manual yang sudah dimiliki. SIKS saat ini sudah dikembangkan untuk proses layanan arsip statis. Sampai sekarang belum diputuskan untuk open atau close sebab SIKS dirancang spesifik untuk proses bisnis Arsip UGM dan belum tentu dapat digunakan di instansi lain. SIKS dikembangkan dengan Framework CodeIgniter, menggunakan basis data PostgreSQL. Berjalan di server Debian dengan web server Apache. Server berada di Direktorat Sistem Sumber Daya Informasi (DSSDI) dengan konsep Colocation. Sampai saat ini yang tercatat di SIKS ada 31160 arsip tekstual, 13810 arsip foto, 423 arsip gambar, 1283 arsip kaset, dan 238 arsip disk.

SIKS adalah ERMS yang dikhususkan untuk arsip statis format elektronik, sedangkan untuk arsip inaktif Kantor Arsip UGM memiliki Sistem Informasi Kearsipan Inaktif (SIKI). Arsiparis berharap pengelolaan arsip aktif harusnya bisa menggunakan Internal Electronic Mailing System (INEMS). Idealnya ketiga sistem tersebut saling bersinergi karena daur hidupnya saling terkait. Namun, untuk saat ini ketiga 


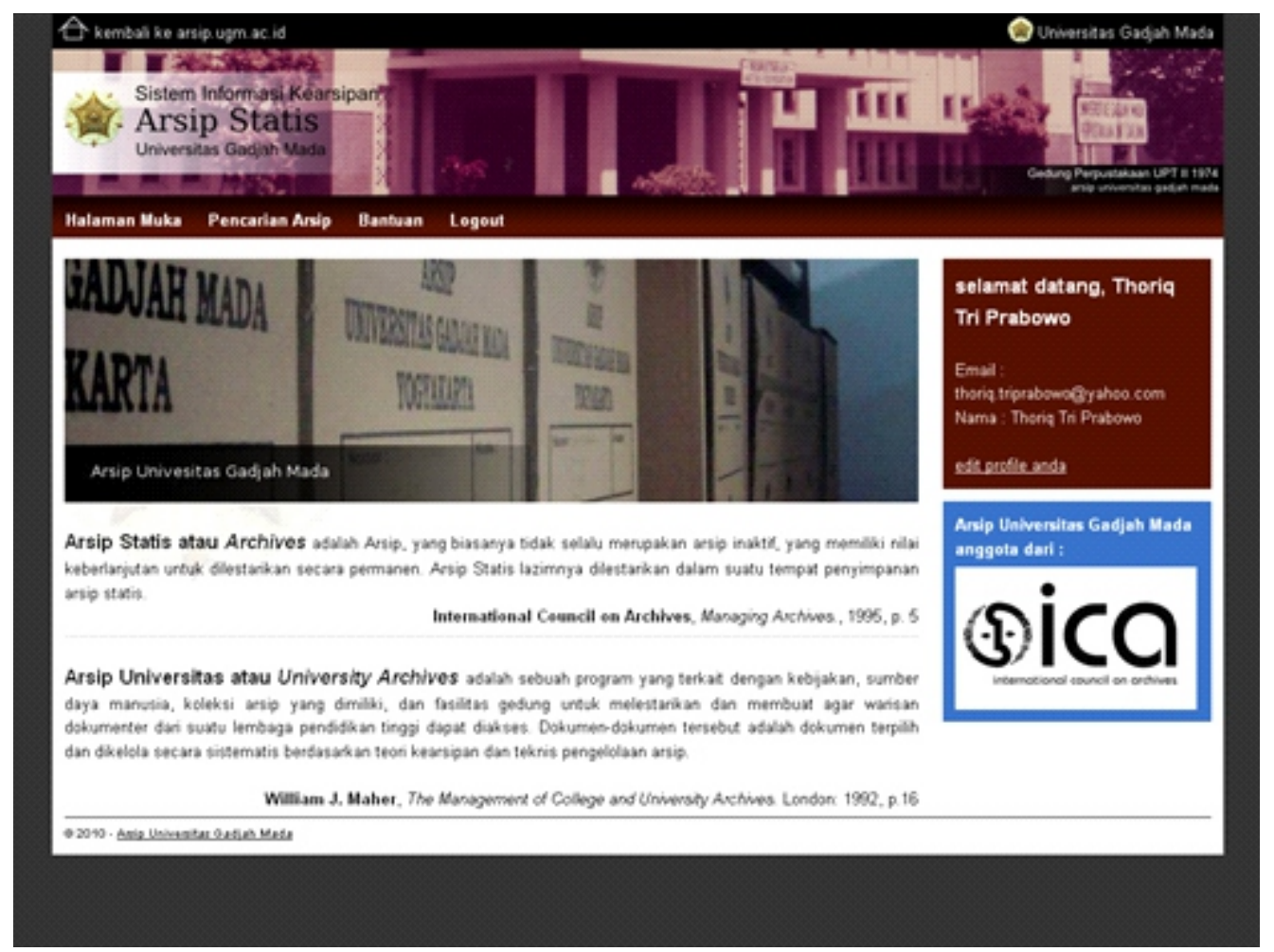

Gambar 2

Login Administrator SIKS

Sumber Gambar: https://siks.arsip.ugm.ac.id/

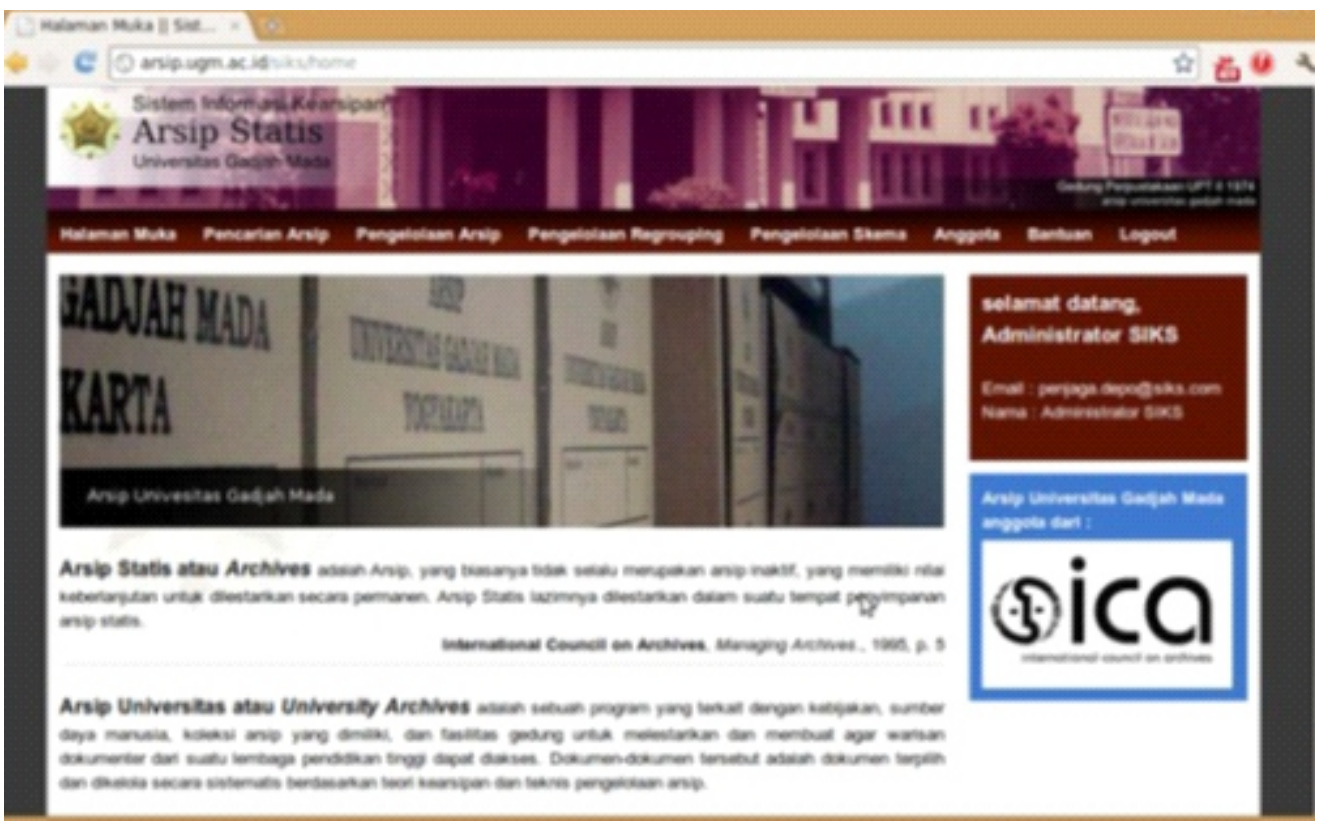

Gambar 2

Login Administrator SIKS

Sumber Gambar: https://siks.arsip.ugm.ac.id/ 


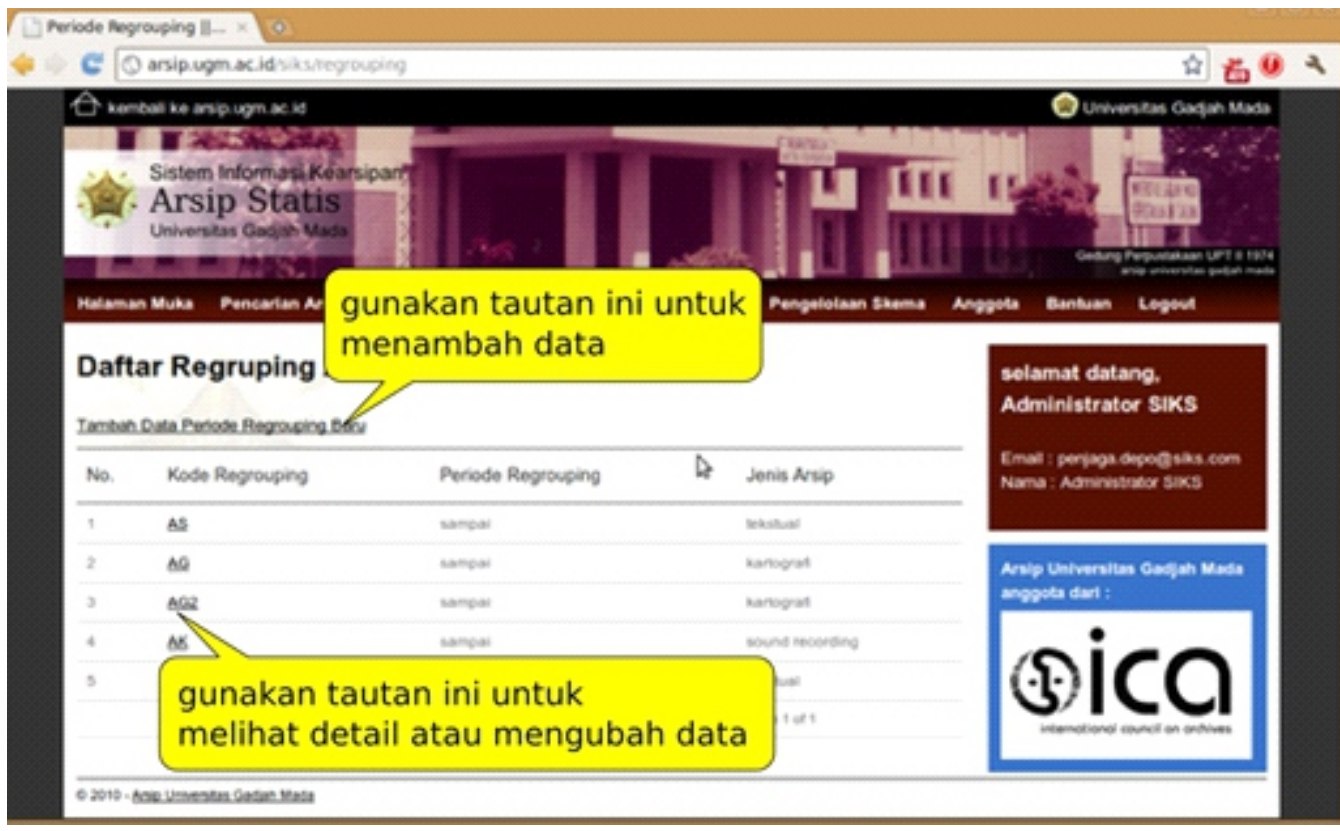

Gambar 3

Menu Administrasi SIKS

Sumber Gambar: https://siks.arsip.ugm.ac.id/

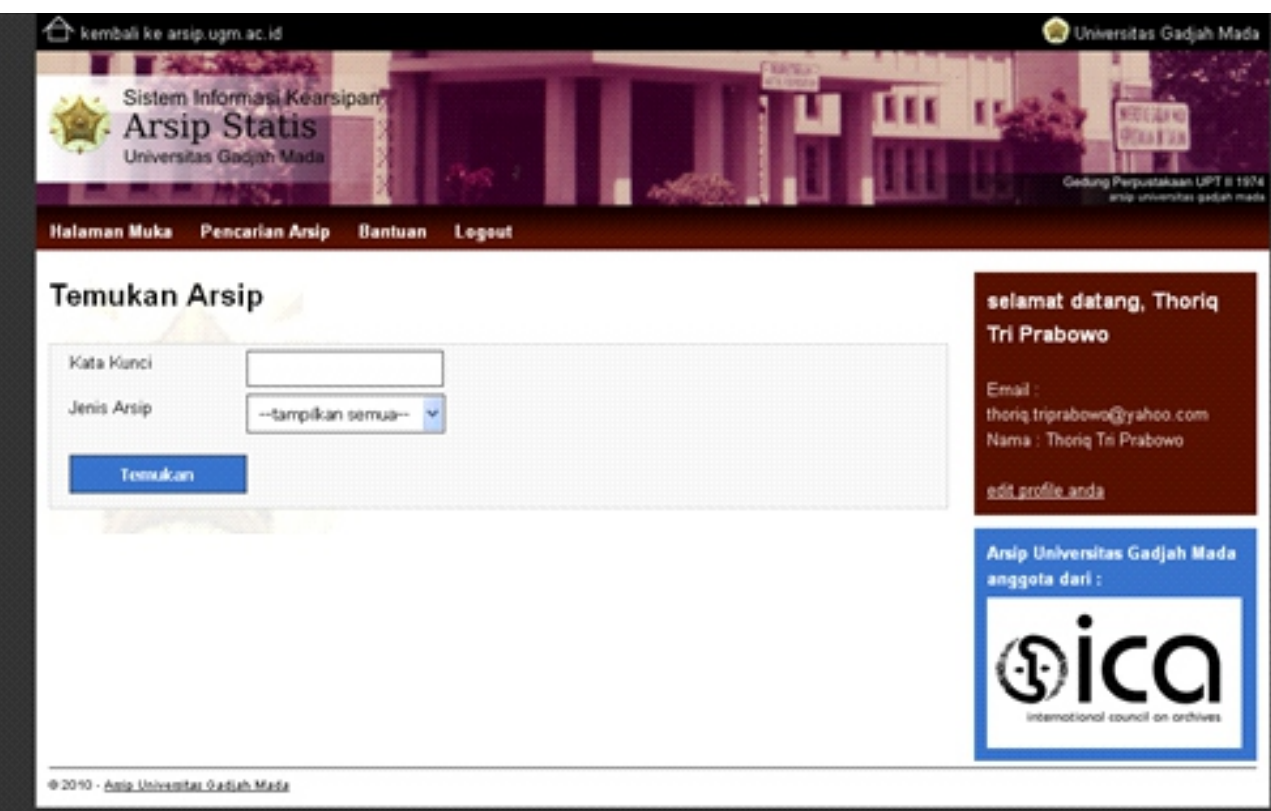

Gambar 4

Menu Pencarian Arsip SIKS

Sumber Gambar: https://siks.arsip.ugm.ac.id/ 
Khazanah: Jurnal Pengembangan Kearsipan, 2021, Vol. 14 (1)

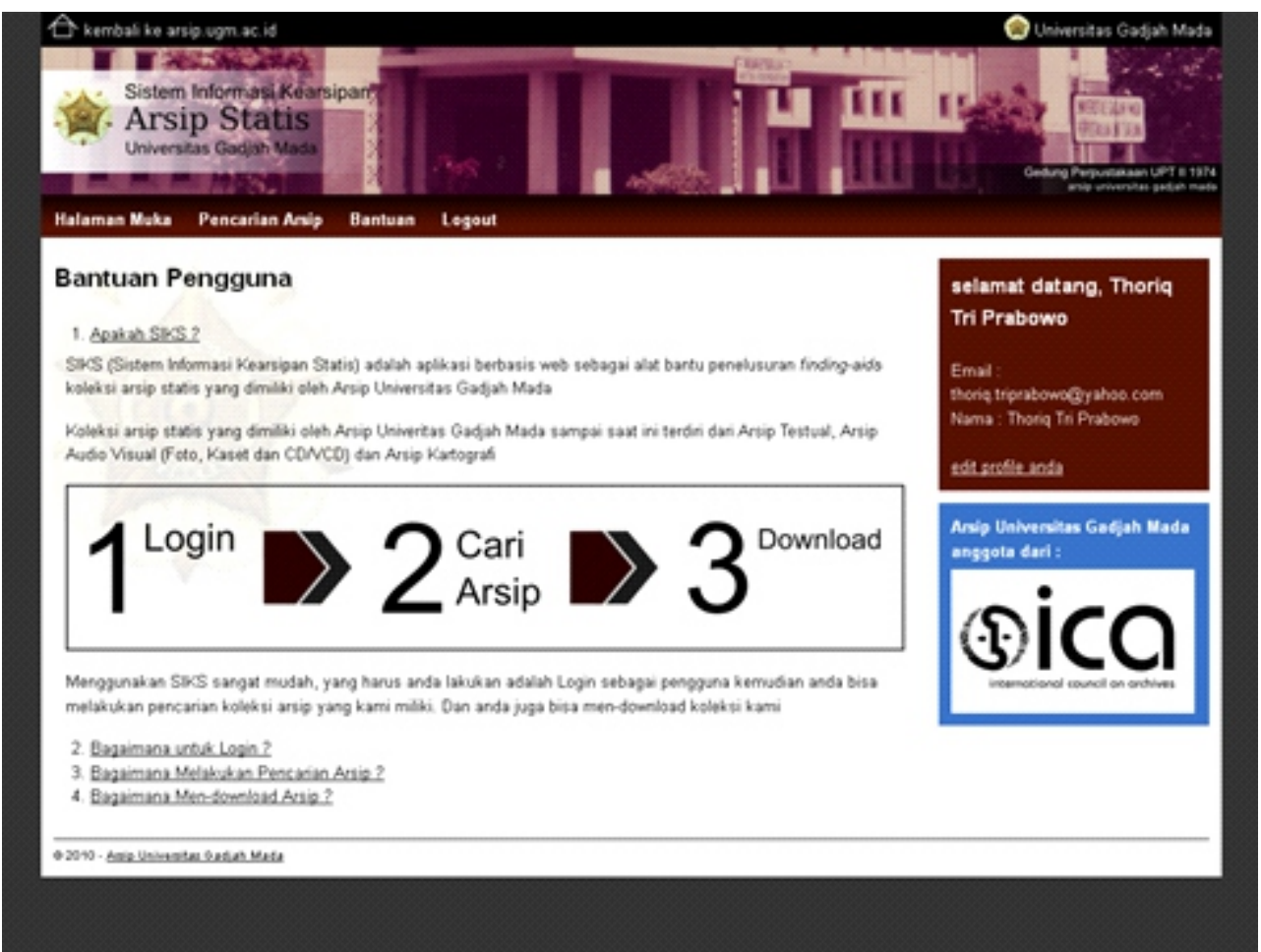

Gambar 5

Fitur Menu Bantuan Pengguna

Sumber Gambar: https://siks.arsip.ugm.ac.id/

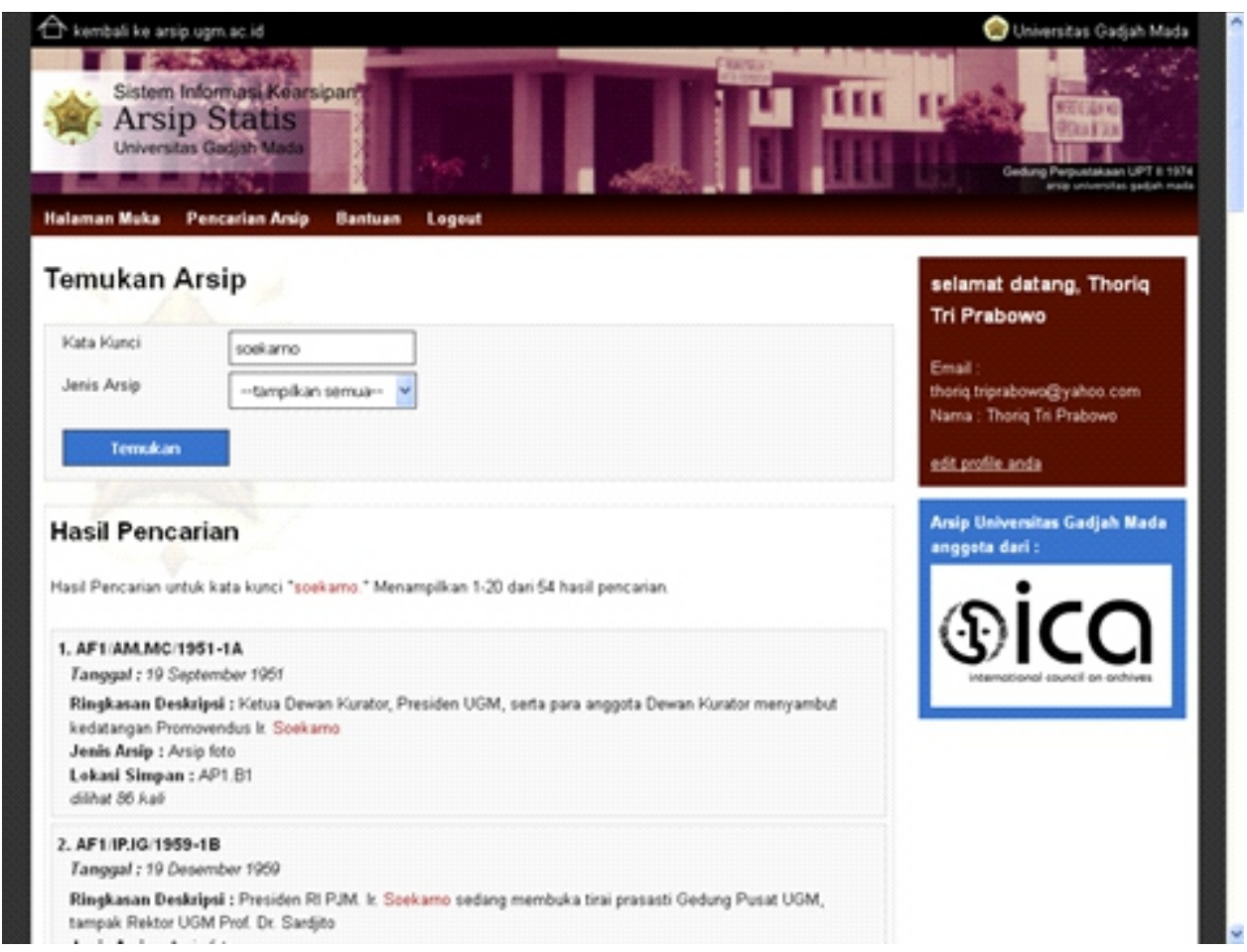

Gambar 6

Contoh Hasil Pencarian pada Semua Keyword Sumber Gambar: https://siks.arsip.ugm.ac.id/ 


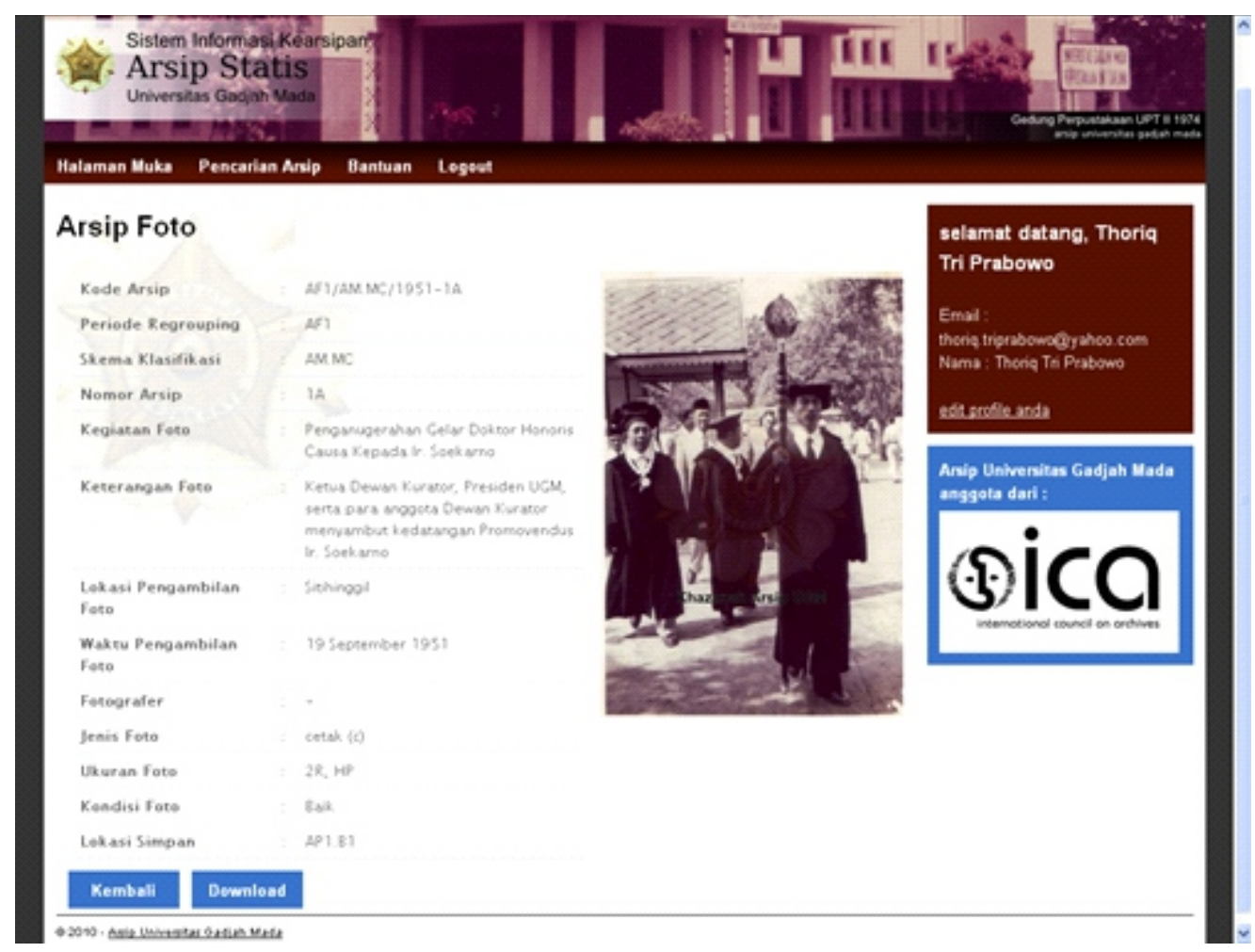

Gambar 7

Contoh Metadata Arsip Elektronik

Sumber Gambar: https://siks.arsip.ugm.ac.id/

sistem tersebut belum terintegrasi. Berikut adalah gambar fitur-fitur yang ada dalam SIKS.

\section{Fitur-Fitur SIKS:}

a. Fitur Data Pengguna

Fitur ini merupakan fitur yang mempersyaratkan bagi pengguna untuk mengisi data pengguna pada SIKS. Adapun beberapa item yang harus diisi pada fitur ini antara lain; username yang berupa email, nama, tangga lahir, alamat, pekerjaan, dan institusi. Setelah melakukan pengisian data pengguna, ternyata tidak ada proses verifikasi. Dengan kata lain pengguna langsung bisa mengakses fitur dari SIKS setelah mengisi data pengguna. Fitur ini lebih identik dengan buku tamu daripada keanggotaan.

b. Fitur Pengelolaan Arsip;

Fitur ini disediakan untuk arsiparis, yaitu digunakan untuk melakukan entry metadata dari arsip. Adapun metadata dari arsip yang dimasukkan antara lain; kode arsip, periode regrouping, skema klasifikasi, nomor arsip, kegiatan, keterangan, lokasi pengambilan, waktu pengambilan, 
perekam, jenis, ukuran, kondisi, dan lokasi simpan dari arsip.

c. Fitur Pencarian Arsip (Temu Kembali);

Dalam fitur ini pengguna difasilitasi satu kolom pencarian umum. Untuk membuat hasil penelusuran lebih spesifik disediakan juga fitur pembatasan hasil penelusuran didasarkan pada jenis-jenis arsip yang meliputi; sound recording, foto, kartografi, tekstual, dan disk. Pengguna dapat memilih menggunakan penelusuran umum ataupun mengombinasikan penelusuran dengan fitur pembatasan tersebut. Hasil dari penelusuran ini adalah metadata dari arsip yang telah disimpan.

d. Fitur Daftar Permintaan Arsip

Fitur ini belum banyak bisa dieksplor karena hanya menampilkan halaman statis yang tidak menyediakan kolom bagi pengguna untuk melakukan aktivitas di dalamnya. Ketika dilakukan uji coba masuk pada fitur ini terdapat informasi yang bahwa "data tidak kami temukan dalam basis data kami”. Kemungkinan fitur ini hanya bisa diakses melalui akun dari admin atau arsiparis. Adapun sesuai dengan nama fiturnya, fitur ini kemungkinan digunakan sebagai kanal untuk membuat daftar permintaan arsip yang diperlukan pengguna.

e. Fitur Bantuan Pengguna

Fitur ini menyediakan bantuan penggunaan situs kepada pengguna dalam format frequently asked questions (FAQ). Adapun beberapa hal yang akan dibantu seputar: gambaran umum mengenai SIKS, cara untuk untuk login pada SIKS, cara melakukan pencarian arsip, dan cara mengunduh arsip. Tidak hanya penjelasan tekstual, pada fitur bantuan ini pengguna juga mendapatkan petunjuk visual yang akan memudahkan pengguna.

\section{Spesifikasi Server ERMS SIKS}

Berdasarkan hasil wawancara dengan informan, server yang digunakan untuk instalasi aplikasi SIKS pada Arsip UGM yaitu seri HP Rack dengan Prossesor Intel Xeon, RAM 2GB, HD 500 GB. Processor yang digunakan tersebut bisa dikatakan cukup cocok untuk server dan atau work station. Namun, untuk ukuran RAM dan penyimpanan internal, spesifikasi yang tersedia masih tergolong kecil, sementara data yang dimasukkan ke dalam sistem sangat mungkin bertambah pada waktu yang akan datang.

\section{Perbedaan Pengelolaan Arsip Elektronik Dinamis dan Statis}

Perbedaan pengelolaan antara 
arsip statis dan dinamis terdapat pada metada yang diolah. Arsip statis lebih rinci sedang dinamis cenderung general. Klasifikasi arsip statis dan aktif juga berbeda. Untuk proses alih media arsip statis harus lebih diperhatikan karena usia material yang relatif tua.

\section{Kelebihan dan Kekurangan SIKS}

Kelebihan:

a. SIKS dibuat sesuai proses pengelolaan arsip yang sudah ada sehingga tidak memerlukan perubahan dalam proses pengelolaan arsip berjalan. Jika di masa yang akan datang ada perubahan pun, dalam proses pengelolaan arsip akan relatif lebih mudah melakukan pengembangan SIKS.

b. SIKS yang disediakan Arsip UGM memungkinkan semua orang, baik sivitas akademika maupun masyarakat umum untuk dapat mengakses SIKS melalui URL: http://arsip.ugm.ac.id/siks/. Pengaksesan SIKS di browser dengan menggunakan perangkat apapun, seperti PC, laptop, dan handphone.

Kekurangan:

a. Untuk saat ini SIKS belum menyediakan tampilan mobile view;

b. Tidak terdapat verifikasi terhadap pengguna;

c. Proses pengembangan jika ada perubahan proses bisnis tidak bisa dengan cepat dilakukan karena terbatasnya sumber daya;

d. Fitur pencarian masih menggunakan fitur pencarian by query seperti biasa sehingga hasilnya kadang tidak begitu memuaskan; dan

e. Dokumen yang berbentuk image belum tersinkronisasi setelah migrasi server SIKS ke server DSSDI.

\section{KESIMPULAN}

Arsip UGM sebagai salah satu layanan penyimpanan dan informasi arsip mempunyai tugas untuk mengumpulkan dan melestarikan dan membuat agar warisan dokumenter dari suatu lembaga pendidikan tinggi dapat diakses. Arsip UGM mempunyai beberapa sistem otomasi untuk mengolah arsip. Beberapa sistem pengelolaan arsip tersebut meliputi; INEMS untuk arsip aktif, SIKI untuk arsip inaktif, dan SIKS untuk arsip statis.

SIKS merupakan salah satu sistem otomasi dalam kearsipan yang mempunyai fungsi untuk mengolah arsip statis, SIKS dapat diakses di http://arsip.ugm.ac.id/siks untuk dapat melakukan pencarian di SIKS pengguna terlebih dahulu mendaftar di SIKS. Secara umum SIKS sudah menerapkan prinsipprinsip ERMS sebagai aplikasi pengolah arsip digital. Namun, dalam implementasinya SIKS ini masih memiliki beberapa catatan yang perlu menjadi evaluasi, yaitu: server sering 
susah diakses, proses pengembangan jika ada perubahan proses bisnis tidak bisa dengan cepat dilakukan karena terbatasnya sumber daya, fitur pencarian masih menggunakan fitur pencarian by query seperti biasa sehingga hasilnya kadang tidak begitu memuaskan, dan tidak adanya proses verifikasi bagi pengguna.

Sebagai rekomendasi SIKS, memerlukan beberapa perbaikan seperti: upgrade server agar akses lebih mudah dan cepat, penambahan fitur pencarian yang tidak hanya berdasarkan query, dilakukannya proses verifikasi bagi pengguna, perlu dikembangkanya model pencarian tingkat lanjut misalnya pencarian dengan boolean operator, dan perlunya sinkronisasi data terutama setelah migrasi server dan perlu ditambah sumber daya manusia khususnya SDM bidang teknologi informasi.

\section{DAFTAR PUSTAKA}

Azmi. (2008). Analisis Pengelolaan Arsip Dinamis dan Statis dalam Menjamin Otentisitas dan Reliabilitas Arsip Bagi Kepentingan Publik. Jurnal Kearsipan Organisasi Dan Layanan Kearsipan, 3(1).

Fathurrahman, M. (2018). Pentingnya Arsip sebagai Sumber Informasi. JIPI (Jurnal Ilmu Perpustakaan Dan Informasi), 3(2), 215-225.
Hendrawan, M. R., \& Ulum, M. C. (2017). Pengantar Kearsipan Dari Isu Kebijakan ke Manajemen. UB Press.

International Standardization Organization. ( $\left.\begin{array}{llll}2 & 0 & 0 & 1\end{array}\right)$. International Standard: Information and DocumentationRecords Management - Part 1: General (ISO 15489-1). International Organization for Standardization.

Irawan, M. (2001). Manajemen Arsip: Suatu Pendekatan Kearsipan. Persepsi Suara Badar I.

Maher, W. J. (1992). The Management of College and University Archives. Scarecrow Press.

Mahmudah, A. R., \& Rahmi, L. (2016). Urgensi dan Integritas Arsip dalam Konteks Kebangsaan dan Kesadaran Sejarah. Lentera Pustaka: Jurnal Kajian Ilmu Perpustakaan, Informasi dan Kearsipan, 2(1), 1-8.

Mutmainnah, S., Siregar, E., Sitanggang, G., \& Tanjung, E. (2020). Manajemen Arsip Perguruan Tinggi: Disertai dengan Jadwal Retensi Arsip Perguruan Tinggi.

Prabowo, T. T. (2020). Penerapan Manajemen Pengetahuan dalam Pengelolaan Dokumen di Perpustakaan STIKes Guna Bangsa. Khazanah: Jurnal Pengembangan Kearsipan, 13(1), 17-33. 
Putranto, W. A. (2018). Pengelolaan Arsip di Era Digital: Mempertimbangkan Kembali Sudut Pandang Pengguna. Diplomatika: Jurnal Kearsipan Terapan, 1(1), 1-11.

Undang-Undang Republik Indonesia Nomor 43 Tahun 2009 tentang Kearsipan,(2009).

Rosalin, S. (2017). Manajemen Arsip Dinamis. Universitas Brawijaya Press.

Rustam, M. (2019). Pengelolaan Arsip Elektronik. Universitas Terbuka.

Setiawan, D., \& Hakim, T. D. (2018).
Manajemen Arsip Perguruan Tinggi: Sebuah Analisa SWOT.

Tempo.co. (2003). Indonesia Kehilangan Pulau Sipadan-LigitanNasional Tempo.co.

Wardah, M. (2017). Pengelolaan Arsip Dinamis. LIBRIA, 8(1), Article 1. 